\title{
Avaliação por gestão integrada como modelo de conscientização e seleção na cadeia de suprimentos
}

\author{
Luis Alberto Ccopa Ibarra \\ Universidade Nove de Julho - UNINOVE \\ lybarra@uol.com.br \\ Felipe Araujo Calarge \\ Universidade Nove de Julho - UNINOVE \\ fcalarge@uninove.com.br
}

\section{RESUMO}

Com foco na cadeia de suprimentos, a conscientização e adequação dos fornecedores com relação aos aspectos de gestão de meio ambiente, saúde e segurança do trabalho aproximam-se ao impacto do sistema de gestão da qualidade, visando a garantia de estabilidade do fornecedor com relação à qualidade; propôs-se a se avaliar em conjunto o sistema de gestão ambiental, de saúde e segurança do trabalho. Esta pesquisa procura por meio de auditoria de fornecedor, desenvolver um meio de garantir esta estabilidade e a melhoria contínua nos três âmbitos. Avaliando um fornecedor de histórico em conformidade, sob a ótica desta ferramenta, foram encontrados pontos de melhoria impactantes para ambos, o fornecedor e a empresa, onde a ferramenta foi implantada.

Palavras-chave: Auditoria Integrada. Sistemas de Gestão Integrada. Cadeia de Suprimentos.

\begin{abstract}
With focus on supply chain awareness and adequacy of suppliers with respect to aspects of environmental management and health and safety, approach to the impact of the quality management system; order to guarantee the stability of the supplier regarding quality was proposed to jointly evaluate the system of environmental management and health and safety. This research seeks through auditing vendor, to develop a means to guarantee this stability and continuous improvement in all three areas. Evaluating a provider accordingly under the historical perspective of this tool impactful points of improvement were found for both the supplier and the company where the tool was implemented.
\end{abstract}

Keywords: Integrated Audit. Integrated Management Systems. Supply Chain.

\section{Introdução}

Duas áreas de pesquisas que apresentam significativo crescimento e se correlacionam são: a gestão da cadeia de suprimentos e as metodologias de gestão normatizadas. Os processos de homologação de fornecedores, como o planejamento avançado da qualidade do produto ou Advanced Product Quality Planning APQP; o processo de liberação de processo produtivo, Production Part Approval Process PPAP e a análise de modos e efeitos de falha ou Failure Mode Effect Analysis FMEA visam estabelecer e garantir a estabilidade e a qualidade desde o início do processo.

Por sua vez, o Sistema de Gestão da Qualidade visa a garantia da qualidade interna da empresa que por consequência é diretamente influenciada pela cadeia de suprimentos, todavia a extensão do Sistema da Qualidade para com os fornecedores usualmente não se estende além de contratos com vistas à certificação e requisições de processos de homologação.

A frente que aborda a auditoria de fornecedores avalia apenas o processo e os requisitos diretamente ligados à qualidade, como o abordado pela norma VDA 6.3 (Verband der Automobilindustrie 6.3), a qual fornece base para a auditoria de processo, modalidade de auditoria que procura identificar as falhas, por meio de análise de parâmetros operacionais e do conhecimento técnico dos auditores.

Esta avaliação limita-se apenas a requisições contratuais e eventuais processos de homologação únicos ou superficiais, sendo que todos os requisitos estão relacionados às normas. 
Diversos autores discutem métodos de avaliação de fornecedores, todos aqui representados usam base em ferramentas de estatísticas e com focos diversos relacionados a diferentes categorias de desempenho de fornecedores, conforme o quadro a seguir.

Quadro 1 - Pesquisas relacionadas à avaliação da cadeia de suprimentos e estatística.

\begin{tabular}{|l|l|}
\hline DUEN-YAN et al., 2007 & $\begin{array}{l}\text { Métodos matemáticos de avaliação de } \\
\text { fornecedores utilizando logica fuzzy e a } \\
\text { metodologia Six Sigma }\end{array}$ \\
\hline KOJIMA et al., 2008 & $\begin{array}{l}\text { Programação estocástica para avaliação de } \\
\text { sistemas Just-in-Time }\end{array}$ \\
\hline BANOMYONG et al., 2011 & $\begin{array}{l}\text { Frameworks de avaliação relacionando custo, } \\
\text { tempo e confiabilidade }\end{array}$ \\
\hline SHARMA et al., 2007 & $\begin{array}{l}\text { Avaliação hierárquica de processos associada } \\
\text { ao Balance Score Card na avaliação da cadeia } \\
\text { de suprimentos }\end{array}$ \\
\hline
\end{tabular}

Fonte: Elaborado pelos autores.

Paralelamente, foram levantadas pesquisas relacionadas à conscientização e adequação da cadeia de suprimentos aos sistemas de gestão, conforme o quadro abaixo:

Quadro 2 - Pesquisas relacionadas à avaliação da cadeia de suprimentos e conscientização.

\begin{tabular}{|l|l|}
\hline ZHU et al., 2010 & $\begin{array}{l}\text { Análise de portfólio pela análise analítica da rede de } \\
\text { processos, avaliando as diferentes iteraç̃os entre } \\
\text { fornecedores e subfornecedores na gestão de cadeia } \\
\text { sustentável }\end{array}$ \\
\hline ADIVAR et al., 2010 & $\begin{array}{l}\text { Modelos de planejamento otimizados para a melhoria } \\
\text { na participação social, aprimorando o impacto social da } \\
\text { cadeia de suprimento a partir de diretrizes }\end{array}$ \\
\hline SU et al., 2008 & $\begin{array}{l}\text { Métodos de avaliações na cadeia de suprimentos a } \\
\text { partir da visão institucional, estruturando a cadeia de } \\
\text { fornecimento a atingir requisitos ambientais e sociais, } \\
\text { estabelecidos pela empresa }\end{array}$ \\
\hline
\end{tabular}

Fonte: Elaborado pelos autores.

Este estudo procura propor uma estrutura de auditoria integrada para a avaliação ponderada de fornecedores, desta maneira permite não apenas um acompanhamento de melhoria contínua, como também um indicador de desenvolvimento de fornecedores para a comparação entre eles e a seleção do fornecedor preferencial.

Atingindo este resultado, um controle da saúde global envolvendo mais de um aspecto pode ser conquistado, podendo se gerenciar não apenas fornecedores que apresentam menores impactos ambientais, mas gerencialmente encorajá-los e guiá-los a uma gestão sustentável, nos âmbitos de meio ambiente e também de saúde e segurança ocupacional.

A empresa envolvida na pesquisa optou por utilizar um fornecedor que já possuía um longo histórico de desenvolvimento e melhorias, para avaliar a capacidade de indicar áreas defasadas e oportunidades de melhoria da ferramenta, esta empresa em questão fornece serviços de calibração e não possuía histórico de não conformidades graves ou de serviços não conformes.
Nesta lacuna, a pesquisa toma sua função, identificando uma das possíveis metodologias de avaliação da cadeia de fornecedores, sob a ótica dos sistemas de gestão integrados, sendo para este estudo, utilizadas as normas NBR ISO 9001:2008, NBR ISO 14001:2004 e OHSAS 18001:2007.

Desta forma, estipulou-se uma questão central para a pesquisa e duas questões auxiliares para avaliar a utilidade da metodologia.

Q1 -É possível se desenvolver um método de auditoria que avalie aspectos de eficiência e adequação aos requisitos das normas, mesmo em empresas sem sistemas de gestão formais?

Qa1 - Estes dados são válidos para a métrica da eficiência do fornecedor e para auxiliar a melhoria contínua do fornecedor?

Qa2- Estes dados podem ser utilizados como métrica para influenciar a escolha do fornecedor preferencial?

Para responder a estas perguntas, este estudo foi estruturado em duas fases: introdução aos conceitos de sistemas de gestão, acompanhado pelo estudo de caso com o desenvolvimento e aplicação da ferramenta de análise.

\section{Desenvolvimento do estudo}

\subsection{Sistemas de Gestão e relacionamentos na cadeia de suprimento}

O tema de gestão ambiental sempre esteve presente nas últimas décadas, tendo em vista que no ano de 1991 já se mostrava em relatórios de resultados fiscais, os investimentos relacionados à gestão ambiental. Após a revisão da SEC Security and Exchange commission $\mathrm{n}^{\circ}$ 6835 e do Boletim contábil de 1992; estes documentos obrigavam todas as empresas a divulgar qualquer dano ou perda relacionada a problemas ambientais em seus relatórios de rendimentos fiscais.

Estes dados geraram um início de competição, situação que se tornou um fator de vantagem competitiva o investimento na gestão ambiental (FEKRAT et al., 1996), porém a normalização da gestão ambiental, sucedeu-se em 1993, com o início das séries NBR ISO 14000, norma internacional que descreve os requisitos básicos para um sistema de gestão ambiental.

Os primeiros estudos de relacionamento dentro da cadeia de suprimento foram exclusivamente voltados para a gestão da qualidade, o foco na qualidade total e qualidade garantida, estes modelos tiveram suas discussões iniciadas em 1994, quando começaram a aparecer padrões de modelos de gestão dentro da cadeia de suprimentos relacionados à gestão da qualidade total TQM (BESSANT 
et al., 1994). Estudos em gestão da qualidade e qualidade assegurada na cadeia continuaram evoluíram a partir da revisão da norma NBR ISO 9001:2000, alavancando as relações de influência entre empresas na cadeia de suprimentos (SROUFE et al., 2008).

As normas de gestão utilizadas nesse estudo são: as NBR ISO 14001:2004, NBR ISO 9001:2008 e OHSAS 18001:2007, estas normas possuem como objetivo, definir os requisitos básicos dos sistemas de gestão da qualidade, ambiental, saúde e segurança ocupacional, respectivamente.

\subsection{Sistemas de gestão normalizados}

Sistemas de gestão apresentam como objetivo a padronização das operações e os meios de gestão, com a finalidade de garantir uma estrutura de controle robusta e capaz, para atingir os objetivos estipulados pelas empresas e pelas pressões externas como: clientes, governo, leis e semelhantes.

Diversos estudos apresentam modelos de integração e de estruturação do sistema de gestão, em sua revisão atual as normas abordam o método de estruturação a partir da visão de processos, mostrando as interações entre áreas administrativas e processos internos e suas respectivas influências das gestões.

Ilustrado na figura a seguir, estão apresentados cinco núcleos fundamentais e alguns dos principais processos envolvidos, com suas correlações diretas, contudo diversas correlações de causa e dependência podem ser estruturadas a partir desta estrutura.

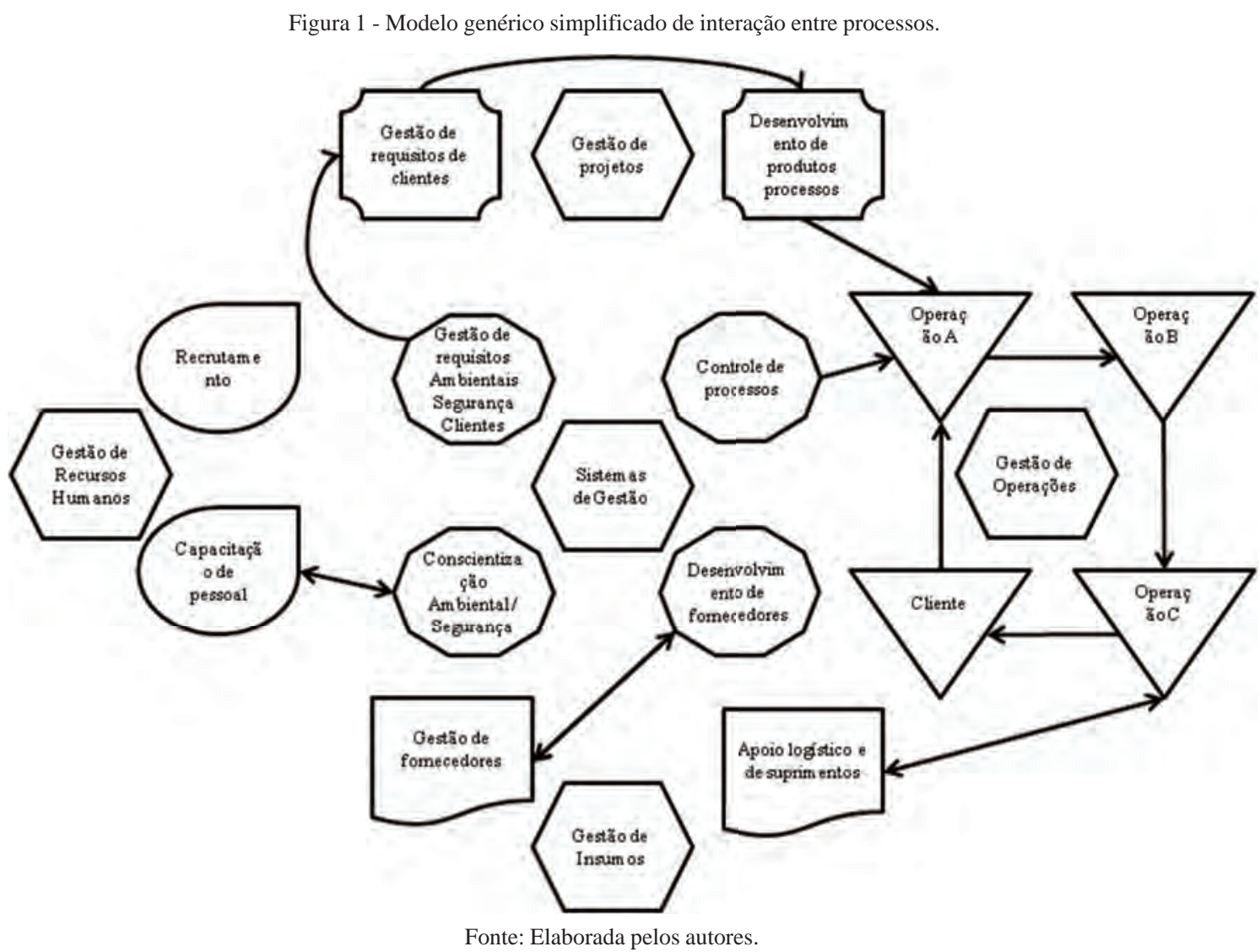

Seguindo estas características, são estipulados os escopos das normas de gestão utilizadas no estudo, com os focos em Qualidade, Meio Ambiente, Saúde e Segurança Ocupacional, conforme as descrições acima.

\subsubsection{NBR ISO 9001}

Esta norma tem como objetivo especificar requisitos para um sistema de gestão da qualidade, em uma organização que necessita demonstrar capacidade de fornecer produtos, de acordo com as necessidades do cliente e requisitos estatutários e regulamentares aplicáveis, assim como possuir capacidade de aumentar a satisfação do cliente, por meio da melhoria contínua do sistema e da capacidade de assegurar a conformidade do produto produzido com relação aos requisitos do cliente (ASSOCIAÇÃO BRASILEIRA DE NORMAS TÉCNICAS, 2008).

Em suma, esta norma focaliza capacitar uma organização com relação à conformidade dos requisitos de clientes, porque funciona para avaliar os processos e os projetos, numa situação presente ou uma estimativa futura, fator que permite aos produtos atuais tenham um processo robusto. 
Outro aspecto positivo analisado situa-se em que todo projeto que for desenvolvido, também deve apresentar estas características e que este sistema esteja em desenvolvimento contínuo para a sua melhoria. A condução deste sistema apoia-se em decisões tomadas em fatos e não em conformidades gerenciadas e controladas.

\subsubsection{NBR ISO 14001}

Esta norma especifica os requisitos relativos a um sistema da gestão ambiental, permitindo a uma organização desenvolver e implementar uma política e objetivos, os quais considerem tanto os requisitos legais e outros requisitos por ela subscritos e informações referentes aos aspectos ambientais significativos. Aplica-se aos aspectos ambientais que a organização identifica como: aqueles que possa controlar e aqueles que possa influenciar.

Em sua constituição, esta norma não estabelece critérios específicos de desempenho ambiental (ASSOCIAÇÃO BRASILEIRA DE NORMAS TÉCNICAS, 2004), de forma semelhante à NBR ISO 9001: 2008, também apresenta como objetivo um sistema de gestão, com a especificidade de garantir que a empresa possua um método de gestão de seus impactos ambientais, ou impactos que a organização tenha capacidade de influenciar. Por outro lado, esta norma não estabelece metas, mas coloca em sua premissa a melhoria contínua do sistema.

Estas metas são: o aumento da eficiência do sistema, redução de impactos e a maior conscientização dos colaboradores e da comunidade, onde a organização está inserida, atendendo também os requisitos regulamentares da região onde suas instalações físicas estão presentes.

\subsubsection{OHSAS 18001}

Esta Norma, Occupational Health and Safety Assessment Series (OHSAS) especifica os requisitos relativos a um sistema de gestão da segurança e saúde do trabalho, para permitir que uma organização controle os seus riscos para a Saúde e Segurança do Trabalho (SST) e melhore o seu desempenho da SST. Não especifica os critérios de desempenho específicos da SST, nem fornece especificações detalhadas para a concepção de um sistema de gestão (OHSAS 18001, 2007).

A última das normas usadas no estudo, a OHSAS 18001 tem como seu objetivo principal a capacitação de uma organização em implantar, manter e melhorar um sistema de gestão relacionado à segurança e saúde ocupacional; redução e eliminação de riscos, atendimento a legislação local e conscientização dos colaboradores com relação à segurança, de forma similar a norma NBR ISO 14001, a OHSAS 18001, também não estabelece metas ou modelos de avaliação, exceto por meio de auditoria, mas estipula em sua premissa a melhoria.

\section{Conceitos iniciais de integração}

Inicialmente neste cenário, restringindo apenas a três normas de sistemas de gestão, o conceito de integração, ou seja, a união destes sistemas pode parecer simples, porém em muitos casos as estruturas desenvolvidas para cada sistema podem dificultar ou contradizer os objetivos dos outros sistemas e esta temperança sutil é uma das maiores dificuldades no sistema.

Neste conceito, deve-se criar um questionamento que abre caminho a duas estruturas diferentes: integrar ou adicionar. Deve-se também transformar os sistemas em uma única estrutura ou desenvolver de forma mais complexa uma estrutura central, onde as outras se tornam módulos a serem instalados.

No conceito de adicionar sistemas é possível criar ilhas isoladas de gerenciamento, as quais podem acarretar situações onde os objetivos tendem a sofrer maiores dificuldades em ser atendidos, por meio de barreiras criadas pela falta de alinhamento (SAMPAIO, 2012).

Por outro lado, pode-se questionar a possibilidade de se criar uma norma integrada, como as normas Australianas (AS/NZS, 1999) e Neozelandesas (NTS, 1996), que aо invés de apresentar uma norma para cada foco, apresenta uma norma de sistema de gestão com foco em qualidade, gestão ambiental e gestão de saúde e segurança ambiental; porém ao se continuar nesta linha de raciocínio, caso qualquer uma das normas específica venha a sofrer revisão, a norma integrada também necessita de revisão.

No surgimento de novas normas necessárias, a norma integrada sofreria revisão; neste conceito a necessidade de revisão desta norma integrada, apresentaria uma velocidade demasiadamente grande para se permitir tempo para a implementação, adequação e certificação da norma, desconsiderando o volume monetário que iria ser gerado, a partir das consultorias e certificadoras para a auditoria desta norma (KARAPETROVIC, 2004).

\subsection{Modelos de integração}

Considerando para esta análise apenas sistemas integrados, necessita-se definir como estruturar de forma eficiente estes sistemas a fim de reduzir ou eliminar ambiguidades por deficiências de definição de objetivos, responsabilidades e metas.

\subsection{Níveis de integração}

Antes de avaliar o modelo de integração, o conceito de nível deve ser abordado com o intuito de estabelecer objetivos, pois a definição de um nível de integração pode definir de forma decisiva o rumo e a estrutura a se adotar. 
Em sua análise mais simples o sistema de gestão pode apresentar três níveis de integração: a correspondência, a generalização e a integração:

\subsubsection{Correspondência}

Estudo das similaridades entre os sistemas, alinhamento entre as principais tarefas para a redução as redundâncias criadas pelos sistemas paralelos, unificação de documentos e redução das ambiguidades. Em resumo, pode-se estabelecer como objetivo alguns itens:

- Redução de documentos e registros.

- Redução de burocracia.

- Redução de custos pela melhor utilização dos recursos dedicados ao sistema.

- Simplificação das auditorias internas e externas.

Este nível de integração pode ser considerado como o modelo inicial da integração de sistemas, um passo adiante desta estrutura se encontra o sistema de generalização.

\subsubsection{Generalização de sistemas}

Este passo tem como objetivo estabelecer um modelo genérico que compreenda todas as necessidades dos sistemas existentes e a ser implantado na organização, de forma a estruturar como um modelo de melhoria contínua, estruturando-o no ciclo PDCA, os itens que caracterizam esta etapa, podem ser listados como um complemento da correspondência entre sistemas:

- Maior foco nas inter-relações - aumento da sinergia entre sistemas e melhor visão dos trade-offs entre sistemas.

- Objetivos são bem definidos, acompanhados e balanceados em conjunto.

- Responsabilidades e organizações são definidas em apenas uma estrutura.

Este passo de integração já apresenta melhorias significativas com relação ao passo de correspondência pelo fato de eliminar barreiras entre sistemas, os objetivos ainda são definidos de forma separada, porém de maneira que siga um alinhamento vertical mais sólido em relação às suas integrações.

\subsubsection{Integração entre sistemas}

Etapa final na integração dos sistemas, além de todas as características anteriores, esta etapa é caracterizada pelo objetivo de se desenvolver uma cultura organizacional, um passo ambicioso para a estruturação da empresa, tem como objetivo os recursos internos e externos, ganhos não apenas internos à organização, mas também as melhorias externas, a fim de atingir um desenvolvimento mais sustentável e com maior responsabilidade social. (JØRGENSEN, 2008).

\section{Desenvolvimento da metodologia de auditoria}

O método de auditoria para validação surgiu em conjunto com as normas de qualidade visando à garantia da qualidade do produto e serviço, evidenciando a manutenção de um sistema que garanta estes resultados.

Algumas pesquisas foram encontradas em relação a auditorias, (MONDRAGON et al., 2011) estuda indicadores de desempenho e integração em cadeias de suprimento com logística reversa, com foco no gerenciamento de estoques, estoques intermediários de produtos a lançar no mercado e devoluções.

Outros autores também discutem a metodologia de auditoria, como a auditoria de escaneamento rápido, pela qual uma serie de dados pré-definidos servem de entrada para um sistema que gera uma lista de possíveis melhorias e ou reestruturações para o aumento da eficiência e desempenho financeiro (CHILDERHOUSE et al., 2011) e (ATILGAN et al., 2011).

Muitos dos métodos de auditoria encontrados em pesquisas estão apenas ou principalmente, focados em modelos matemáticos ou "ferramentas de análise rápida de estoques”, para uma maior flexibilidade e capacidade de resposta, entretanto ainda é escasso o material sobre modelos de programas de auditoria para a garantia dos sistemas de gestão.

A ferramenta proposta nesta pesquisa fornece outra visão para a análise de fornecedores com o intuito de melhorar o desempenho, por meio de uma análise consciente dos objetivos e metas estabelecidos, a eficiência da gestão e do desempenho nos três pilares fundamentais de uma gestão integrada: a gestão da qualidade, ambiental, de saúde e segurança ocupacional.

\subsection{Desenvolvimento do Checklist}

A ferramenta desenvolvida para a auditoria é um checklist onde constam perguntas item a item, exemplos ou condições que servem de referência ao auditor durante toda a auditoria. Estes itens são classificados e ordenados de forma a permitir um fluxo lógico por toda a organização e por áreas agrupadas, conforme ilustrado na figura a seguir.

Esta organização de tópicos permite de uma forma otimizada realizar a auditoria, seguindo de maneira mais fiel o fluxo de valores de uma empresa. 


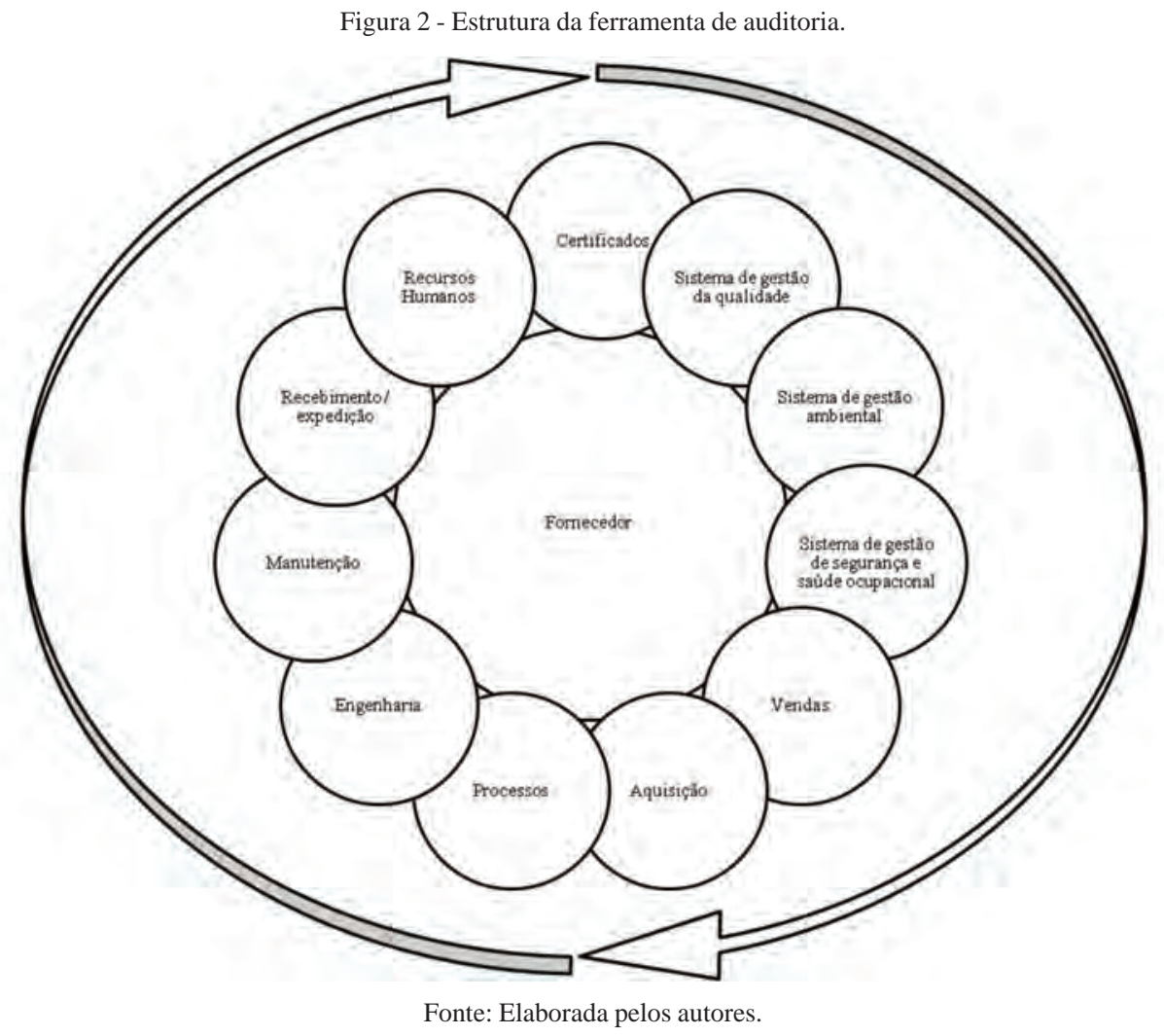

Começando a auditoria com a verificação de certificados existentes adquiridos pela empresa, estabelecendo o primeiro background do fornecedor, iniciando a auditoria com tópicos sobre gestão da qualidade, sequencialmente pelos sistemas de gestão ambiental, de saúde e segurança ocupacional; áreas chave em toda a organização são pontos de verificação, como pelo processo comercial incluindo vendas, aquisição, processos, a engenharia ou desenvolvimento de processo/produto, manutenção, recebimento e expedição. Concluindo com o departamento de recursos humanos.

O checklist além de fornecer o roteiro base para a auditoria, também pode ser utilizado como indicador ao final, pois pontua em três categorias a eficiência: Atende ou OK, Deficiente e Não atende ou NOK. Considerando que cada fornecedor possuir características diferentes foi adicionado a coluna "não aplicável” ou "NA” para atender todas as situações possíveis, de fornecedores de serviços a produtos, matéria prima ou serviços complementares externos.

Para o melhor discernimento destes fatores foi criada a classificação ou "criticidade" do item, onde além de variar as 4 categorias: OK somando 5 pontos, Def. que soma 1 ponto, NOK não somado pontos e NA que invalida a pergunta; estes valores recebem o fator multiplicador variando de 1 a 4 para a classificação de item comum a crítico. Desta forma, os resultados variam de 1 a 20, entre os tópicos, permitindo uma liberdade de classificação de prioridades e necessidades, ao atender a realidade da empresa auditora, abaixo um quadro exemplifica as possíveis pontuações.

Quadro 3 - Pontuações possíveis no checklist.

\begin{tabular}{|l|l|l|l|l|}
\hline \multicolumn{1}{|c|}{ Resultado/ Criticidade } & \multicolumn{1}{|c|}{1} & \multicolumn{1}{|c|}{$\mathbf{2}$} & \multicolumn{1}{|c|}{$\mathbf{3}$} \\
\hline OK (5 pontos) & $\begin{array}{l}\text { Valor } 5 \\
\text { Baixa prioridade em } \\
\text { Conformidade }\end{array}$ & $\begin{array}{l}\text { Valor 10 } \\
\text { Baixa - Média prioridade em } \\
\text { Conformidade }\end{array}$ & $\begin{array}{l}\text { Valor 15 } \\
\text { Média - Alta prioridade em } \\
\text { Conformidade }\end{array}$ & $\begin{array}{l}\text { Valor 20 } \\
\text { Alta prioridade em } \\
\text { Conformidade }\end{array}$ \\
\hline $\begin{array}{l}\text { Deficiente } \\
(1 \text { ponto })\end{array}$ & $\begin{array}{l}\text { Valor 1 } \\
\text { Baixa prioridade com } \\
\text { deficiências }\end{array}$ & $\begin{array}{l}\text { Valor 2 } \\
\text { Baixa - Média prioridade com } \\
\text { deficiências }\end{array}$ & $\begin{array}{l}\text { Valor 3 } \\
\text { Média - Alta prioridade com } \\
\text { deficiências }\end{array}$ & $\begin{array}{l}\text { Valor } 4 \\
\text { Alta prioridade com deficiências }\end{array}$ \\
\hline NOK (0 ponto $)$ & $\begin{array}{l}\text { Valor 0 } \\
\text { Baixa prioridade em Não } \\
\text { Conformidade }\end{array}$ & $\begin{array}{l}\text { Valor 0 } \\
\text { Baixa - Média prioridade em } \\
\text { Não Conformidade }\end{array}$ & $\begin{array}{l}\text { Valor 0 } \\
\text { Média - Alta prioridade em Não } \\
\text { Conformidade }\end{array}$ & $\begin{array}{l}\text { Valor 0 } \\
\text { Alta prioridade em Não } \\
\text { Conformidade }\end{array}$ \\
\hline
\end{tabular}

Fonte: Elaborado pelos autores. 
Além da divisão de categorias em relação à pontuação, o checklist também é dividido em capítulos, onde cada capítulo trata de uma determinada área, verificando os requisitos aplicáveis relacionados às três normas em toda a empresa.

Abaixo segue um resumo de cada capítulo do checklist:

\subsubsection{Certificados}

Este primeiro item é curto, porém auxilia a adequação dos fornecedores aos sistemas de gestão, pois penaliza, caso o fornecedor não o tenha. Todavia, também abre a liberdade de não penalizar, quando o sistema implicar em custos ou quebras de acordos comerciais que inviabilizam a condição de fornecimento, o objetivo é verificar se existem os certificados e se estão em vigência para evidenciar os esforços do fornecedor.

\subsubsection{Sistema de gestão da qualidade}

Este item cobre os conteúdos fundamentais do sistema de gestão da qualidade como a análise crítica pela direção, adequação da política, programa de auditoria interna, metrologia, controle de documentos e a conscientização dos colaboradores.

\subsubsection{Sistema de gestão ambiental}

De forma similar ao sistema de gestão da qualidade, este item discorre nos itens relacionados aos fundamentos da gestão ambiental, adequação aos requisitos legais comuns a qualquer atividade comercial, conscientização dos colaboradores, controle de resíduos e atendimento a emergências ambientais.

\subsubsection{Sistema de gestão de segurança e saúde do trabalho}

Similar aos capítulos anteriores, porém com foco no sistema de gestão de SST, treinamentos de brigada, simulados de emergência e evacuação, adequação à legislação e todos os itens compreendidos aos fundamentos da gestão de SST.

\subsubsection{Vendas}

Este capítulo cobre o processo de vendas avaliando como é feito o levantamento de satisfação do cliente, se os funcionários estão cientes e conscientes sobre os aspectos de gestão ambiental e de SST. Como é feita a troca de informações e canal de comunicação com os clientes, rastreabilidade, controle de documentos, avaliação de prazos e outros itens tangentes aos fundamentos do sistema.

\subsubsection{Aquisição}

Analisa o processo de aquisição, avaliando se os funcionários estão cientes e conscientes sobre os aspectos de gestão ambiental e de SST. Como é feita a troca de informações e canal de comunicação com os demais setores, rastreabilidade, controle de documentos, avaliação de prazos e outros itens tangentes aos fundamentos do sistema.

\subsubsection{Processos}

Avalia a área produtiva, adequação e preparação do processo e dos colaboradores. O planejamento de produção, a estrutura adequada de trabalho, métodos de coleta de resíduos e controles internos com relação a atendimentos de emergências ambientais e de segurança, rastreabilidade, gestão de itens não conformes, controle de documentos e os demais itens aplicáveis à realidade de uma linha de produção genérica.

\subsubsection{Engenharia}

Procura definir como o processo de produção é estruturado, porque avalia como é este planejamento e se os funcionários estão cientes e conscientes sobre os aspectos de gestão ambiental e de SST. De que maneira acontece a troca de informações e o canal de comunicação com os demais setores, rastreabilidade, controle de documentos, avaliação de prazos e outros itens tangentes aos fundamentos do sistema.

\subsubsection{Manutenção}

Analisa o processo de manutenção avaliando se os funcionários estão cientes e conscientes sobre os aspectos de gestão ambiental e de SST. Como é feita a troca de informações e o canal de comunicação com os demais setores, planejamento de manutenção preventiva, rastreabilidade, controle de documentos, e outros itens tangentes aos fundamentos do sistema.

\subsubsection{Recebimento / expedição}

Avalia a continuação processo de aquisição verificando se os funcionários estão cientes e conscientes sobre os aspectos de gestão ambiental e de SST. Como é feita a troca de informações e canal de comunicação com os demais setores, principalmente rastreabilidade, controle de documentos, avaliação de conformidade e outros itens tangentes aos fundamentos do sistema. 


\subsubsection{Recursos humanos}

Completando o ciclo é feita a avaliação deste setor, inicia-se com avaliação da conscientização dos funcionários sobre os aspectos de gestão ambiental e de SST. Controle de documentos e de registros, de que forma sucede-se a troca de informações e o canal de comunicação com os demais setores, rastreabilidade, controle de treinamentos, avaliação de cargo e outros itens tangentes aos fundamentos do sistema.

\section{Resultados}

Após a visita de um auditor interno da empresa, utilizando o checklist de auditoria, alguns resultados inesperados foram encontrados. Apesar do histórico estável da prestadora de serviços em relação às auditorias e isenção de falhas nos serviços prestados com o método de avaliação ponderado, algumas observações pontuais e algumas eficiências abaixo da meta foram encontradas.

Com o apoio desta análise, áreas que antes não eram vistas como deficientes, foram evidenciadas como ineficientes, como a gestão ambiental que não avaliava os produtos químicos quanto à periculosidade e também não possuía os devidos documentos de descarte de resíduos obrigatórios por lei.

Os resultados, como mostra o gráfico abaixo, evidenciam claramente as áreas que estão em conformidade e as áreas que necessitam de auxílio para sua melhoria.

O sistema de gestão da qualidade também apresentou desvios como: a falta de evidência de uma reunião de análise crítica pela direção, com o intuito de avaliar e revisar os resultados e objetivos da empresa.

Figura 3 - Gráfico de resultados por área.

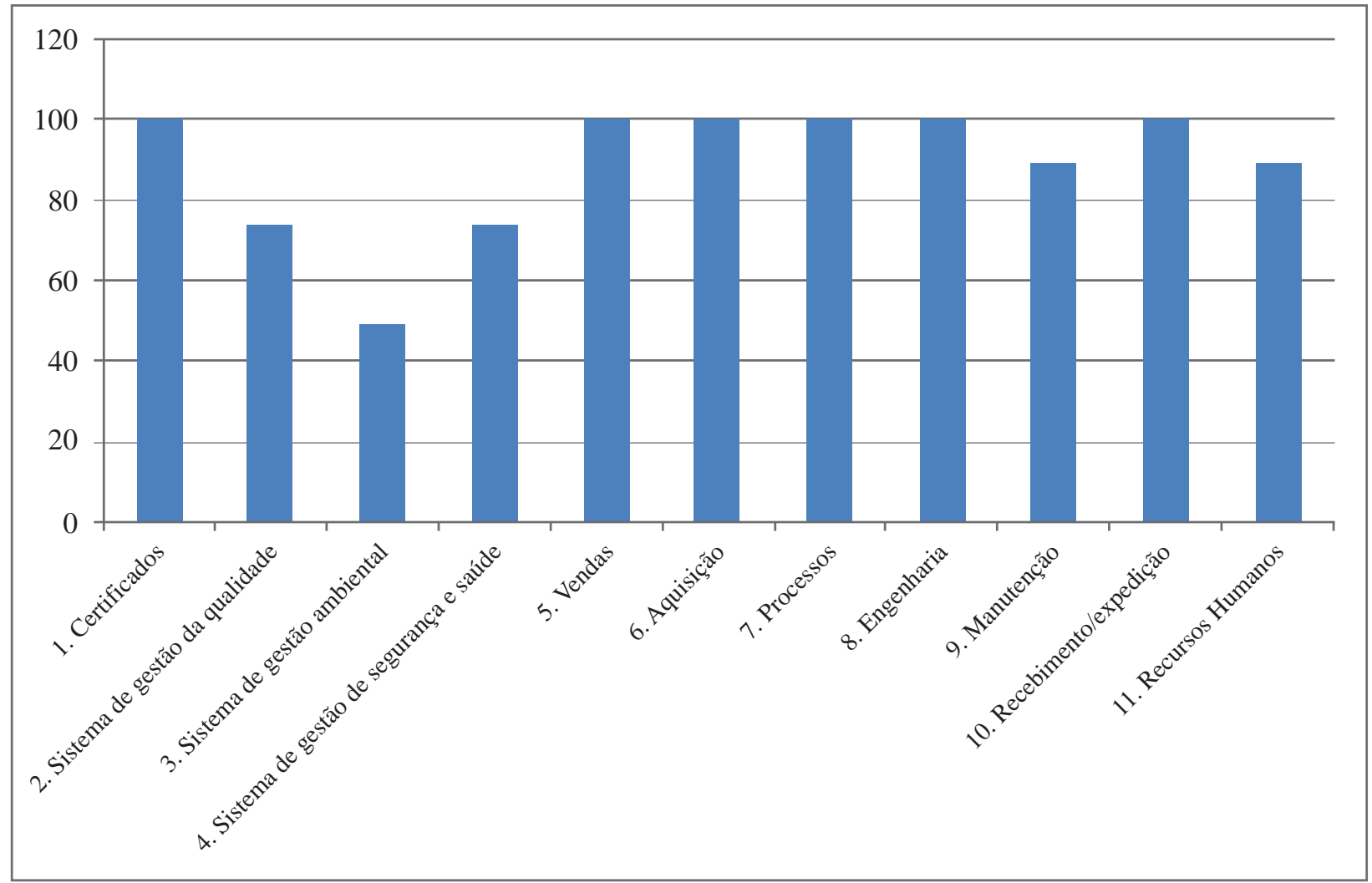

Fonte: Elaborada pelos autores.

Um relatório de ações de melhoria foi desenvolvido pelo cliente e monitorado pelo sistema de gestão, assim as melhorias podem ser acompanhadas e evidenciar novas melhorias e adequações aos sistemas de gestão ambiental, de saúde e segurança ocupacional, as quais não eram exigidas contratualmente pelo fornecedor.

\section{Considerações finais}

As empresas movidas pelo rápido desenvolvimento do mercado e da globalização, tanto a nível global quanto local, começam a sofrer com as pressões externas para a adequação de seus sistemas de gestão. Estas características tornam-se complexas quando levadas ao nível da cadeia de suprimentos, pelo fato de ser diretamente ligada a mudança de cultura e a novas avaliações de "trade offs". 
Ao enfrentar as mesmas pressões, as cadeias de fornecimento tiveram grande crescimento no foco das pesquisas. Os meios de conscientização e adequação dos fornecedores são em muitas situações deficientes para promover uma melhoria contínua.

Esta metodologia foi comprovada neste programa piloto, como um método válido para a conscientização de fornecedores e uma forma de incentivar a melhoria contínua, porque este método fornece de forma estruturada os objetivos a serem atendidos, fundamentados nas normas regulamentadoras e nas legislações nacionais pertinentes ao cenário em que a empresa auditora se enquadra.

Assim, atendendo as premissas da questão da pesquisa e as questões adicionais, a possibilidade de se estruturar um método de auditoria capaz de avaliar os fornecedores, mesmo que o fornecedor não tenha um sistema implantado e podendo servir de indicador para a escolha de fornecedores preferenciais, pela comparação de desempenho.

Vale ressaltar a importância de se estabelecer uma maneira sistemática e evolutiva de se conscientizar e alavancar melhorias na cadeia de suprimentos, uma vez que participando da continuidade do negócio as mesmas passam a ter responsabilidades compartilhadas entre toda a cadeia com relação a desvios e infrações. Este modelo visa não apenas a garantia de menores impactos para o meio ambiente, sociedade e o ser humano, mas também objetiva a segurança de investimento em toda a cadeia, sendo investimento financeiro ou em marketing.

Alguns autores discutem outras formas de se conscientizar os fornecedores da cadeia de suprimentos: análise sobre os métodos sistemáticos para estender os conceitos de sustentabilidade na cadeia de suprimentos (GIMENEZ et al., 2012). Estudo sobre os incentivos de atendimento aos regulamentos e seus impactos no desempenho do sistema de gestão ambiental da empresa (ANTON et al., 2004).

Também o estudo sobre as influências dos contextos culturais na implementação de sistemas de responsabilidade social, abrindo a possibilidade de discussões sobre modelos de influência na cadeia, sob a ótica de diversos sistemas de gestão e a possibilidade de múltiplos agentes de pressão externa para a adequação da cadeia de fornecedores aos sistemas de gestão, que por sua vez implicam em melhores resultados para toda a cadeia, redução de custos por redução de matéria prima, redução de uso de recursos naturais, produtos eco eficientes, redução de riscos à saúde dos colaboradores, melhor conscientização da população de certa região pela mudança de cultura e troca de paradigmas relacionados à segurança, aumento do valor social das empresas participantes da cadeia, entre outras diversas melhorias que influenciam socialmente e economicamente, a partir destas novas abordagens de conscientização (PERRY, 2012).
Outro fator importante a se avaliar é a possibilidade de se desenvolver, homologar e realizar a escolha do fornecedor preferencial para o processo, visando uma melhor eficiência e melhores resultados econômicos pela auditoria e históricos levantados com o auxílio desta ferramenta ou similares.

Portanto, pode-se concluir neste estudo de caso, uma eficiência na obtenção dos indicadores para avaliação, conscientização de fornecedores e seleção na cadeia de suprimentos, utilizando o Sistema de Gestão Integrada.

\section{Referências}

ADIVAR, B. et al. Improving social welfare chain using optimal planning model. Supply Chain Management: An International Journal, v. 15, 2010.

ANTON, W. R. Q.; DELTAS, G.; KHANNAC, M. Incentives for environmental self-regulation and implications for environmental performance. Journal of Environmental Economics and Management, v. 48, 2004.

ASSOCIAÇÃO BRASILEIRA DE NORMAS TÉCNICAS. NBR ISO 9001: Sistemas de Gestão da Qualidade, Requisitos. Rio de Janeiro, 2008. 28 p.

. NBR ISO 14001: Sistemas de Gestão Ambiental, Requisitos com orientações para uso. Rio de Janeiro, 2004. 27 p.

ATILGAN, C.; MCCULLEN, P. Improving supply chain performance through auditing: a change management perspective. Supply Chain Management: An International Journal, v. 16, 2011.

BANOMYONG, R.; SUPATN, N. Developing a supply chain performance tool for SMEs in Thailand. Supply Chain Management: An International Journal, v. 16, 2011.

BESSANT, J.; LEVY, P.; SANG, B. Managing successful total quality relationships in the supply chain. European Journal of Purchasing and Supply Management, v. 1, 1994.

CHILDERHOUSE, P.; TOWILL, D. R. Effective supply chain research via the quick scan audit methodology. Supply Chain Management: An International Journal, v. 16, 2011.

DUEN-YAN, Y.; MEI-LIN, C.; CHING-HSUE, C. A modified two-tuple FLC model for evaluating the performance of SCM: By the Six Sigma DMAIC process. Applied Soft Computing, 2007.

FEKRAT, M. A.; INCLAN, C.; PETRONI, D. Corporate Environmental Disclosures: Competitive Disclosure Hypothesis Using 1991 Annual Report Data. The International Journal of Accounting, v. 31, 1996. 
GIMENEZ, C.; TACHIZAWA, E. M. Extending sustainability to suppliers: a systematic literature review. Supply Chain Management: An International Journal, v. 17, 2012.

HAMIDI, N; OMIDVARI, M.; MEFTAHI, M., The effect of integrated management system on safety and productivity indices: Case study; Iranian cement industries. Safety Science, v. 50, p. 1180-1189, 2012.

JØRGENSEN, T. H. Towards more sustainable management systems: through life cycle management and integration. Journal of Cleaner Production, v. 16, p. 10711080, 2008.

KARAPETROVIC, S.; JONKER J. Systems thinking for the integration of management systems. Business Process Management Journal, v. 10, issue 6, p. 608-615, 2004.

KOJIMA, M.; NAKASHIMA, K.; OHNO, K. Performance evaluation of SCM in JIT environment. International Journal of Production Economics, v. 115, 2008.

MONDRAGON, A. E. C.; MONDRAGON, C. E. C.; LALWANI, C. Measures for auditing performance and integration in closed-loop supply chains. Supply Chain Management: An International Journal, v. 16, 2011.

OHSAS 18001. Sistemas de Gestão e da Saúde do Trabalho, Requisitos. ISO/IEC Directives, 2007.
PERRY, P. Exploring the influence of national cultural context on CSR implementation. Journal of Fashion Marketing and Management, v. 16, 2012.

SALOMONE, R. Integrated management systems: experiences in Italian organizations. Journal of Cleaner Production, v. 16, p. 1786-1806, 2008.

SAMPAIO, P.; SARAIVA, P.; DOMINGUES, P. Management systems: integration or addition? International Journal of Quality \& Reliability Management, v. 29, issue 4, p. 402-424, 2012.

SHARMA, M. K.; BHAGWAT, R. An integrated BSCAHP approach for supply chain management evaluation. Measuring Business Excellence, v. 11, 2007.

SROUFE, R.; CURKOVIC, S. An examination of ISO 9000:2000 and supply chain quality assurance. Journal of Operations Management, v. 26, 2008.

SU, Q.; SHI, J.; LAI, S. Study on supply chain management of Chinese firms from the institutional view. International Journal of Production Economics, v. 115, 2008.

ZHU, Q.; DOU, Y.; SARKIS, J. A portfolio-based analysis for green supplier management using the analytical network process. Supply Chain Management: An International Journal, v. 15, 2010. 
Editoração e impressão:

$$
\begin{aligned}
& \text { S) } \\
& \text { UFRGS }
\end{aligned}
$$

